\title{
Implanted related complications and mortality after gamma nail fsor unstable trochanteric fractures: (a report of 450 consecutive cases)
}

\begin{abstract}
The Gamma nail represents the latest advancement in the treatment of trochanteric fractures combining the principles of intramedullary nailing with almost percutaneous insertion. Despite its mechanical advantages, the gamma nail is not immune to complications like other methods for surgical management of extracapsular hip fractures in the elderly.

The objective of this paper is to assess the outcome of surgical treatment of trochanteric fractures using Gamma nails with focus on its potential per and postoperative complications through a retrospective series of 450 patients managed at the department of Trauma and Orthopedic Surgery A, HASSAN II Teaching Hospital, Fez between January 2010 and January 2016.

Patients aged between 32 and 95 years old (mean age of 67years) with predominantly unstable (type A2 and A3 fractures) $(\mathrm{n}=342,76 \%)$ were involved. Bony union was achieved at an average 3 months in $95.5 \%$ of cases, with satisfactory reduction in $80 \%$ of cases. Parker score averaged 6 (between 6 and 8 ). In all $78(17 \%)$ per and postoperative complications were recorded, of which 17 required surgical revision. 29 deaths were recorded during this period. Other complications include cervical screw cut-out ( 6 cases), proximal femur diaphyseal fractures ( 9 cases), malunion (20 cases), mechanical failure (1 case), implant breakage ( 2 cases), pseudarthrosis (1 case) and failed distal locking (10 cases).
\end{abstract}

Keywords: trochanteric fracture, Gamma nail, implanted related complications
Volume II Issue 3 - 2019

\author{
AM Niandou,' K Lahrach, ${ }^{2}$ A Marzouki, ${ }^{2} \mathrm{~F}$ \\ Boutayeb $^{3}$ \\ 'Resident, Department of Trauma and Orthopedic Surgery A \\ HASSAN II University Hospital Fes, Morocco \\ ${ }^{2}$ Associate Professor, HASSAN II University Hospital Fes, \\ Morocco \\ ${ }^{3}$ Head of Department, HASSAN II University Hospital Fes, \\ Morocco
}

Correspondence: Moussa Niandou Ali, Department of Trauma and Orthopedic Surgery A, HASSAN II University Hospital Fes, Morocco, Tel 00212626250843,

Email moussaniandouali@yahoo.fr

Received: May 20, 2019 | Published: May 27, 2019

\section{Abbreviation: ASA, American Society of Anaesthesiology \\ Introduction}

Trochanteric fractures represent $60 \%$ of proximal femur fractures. They remain one of the major causes of mortality, morbidity and loss of function among the elderly. It poses a major health concern with incidence increasing with aging global population. ${ }^{2,3}$ Various methods of reduction have been developed over the years for the management of these fractures. Bone quality and cervical screw placement have been the main talking points of internal fixation. Despite its numerous advantages: notably enhanced stability of construct, cervical compression and mini-invasive approach, few reports exist in literature on the use of the Gamma nail and its relatively higher rate of complications especially diaphyseal fracture and cephalic screw cutout. ${ }^{4-6}$ The purpose of this study is to assess per and postoperative complication rates in our series and to identify its causes in order enhance Gamma nailing technique in our department.

\section{Methods}

We carried out a descriptive retrospective study involving 450 patients managed for trochanteric fractures in the department of Trauma and Orthopedic Surgery A, Hassan II University Hospital, Fez between January 2010 and January 2016. We excluded patients with pathological fractures and cases of poly trauma. Preoperative checklist list entailed patient demographics, affected side, pre-injury ambulatory status (8), fracture classification and morbidity assessment using American Society of Anesthesiology Score (7) (Table 1,2 and Figure 1). Patients underwent closed reduction internal fixation using the standard gamma nail, $11 \mathrm{~mm}$ in diameter, with a cervicodiaphyseal angle of $130^{\circ}$ and distal locking in all cases. Follow up was done regularly with complete physical exam and routine x-rays each month up to 6 months and twice yearly afterwards. Functional outcome was evaluated according to Parker's rating ${ }^{8}$ and bony union as well as implant related complications were assessed in the course of follow-up.

Table I American Society of Anesthesiology (ASA) score for preoperative morbidity assessment ${ }^{7}$

\begin{tabular}{llll}
\hline & Score ASA & $\mathbf{N}=\mathbf{4 5 0}$ & $\%$ \\
\hline Healthy patient & 1 & 120 & 26 \\
Mild pathology & 2 & 90 & 20 \\
Average Pathology & 3 & 160 & 35 \\
Severe Pathology & 4 & 80 & 17 \\
\hline
\end{tabular}


Table 2 Parker functional score ${ }^{8}$

\begin{tabular}{|c|c|c|c|c|}
\hline Parker score & $\begin{array}{l}\text { yes, without difficulty and } \\
\text { without help }\end{array}$ & $\begin{array}{l}\text { yes, with assistive } \\
\text { device (cane) }\end{array}$ & $\begin{array}{l}\text { yes, with help of } \\
\text { another person }\end{array}$ & Not at all \\
\hline Able to walk inside the house? & 3 & 2 & I & 0 \\
\hline Able to walk inside the house? & 3 & 2 & I & 0 \\
\hline $\begin{array}{l}\text { Able to go shopping, to restaurants or } \\
\text { to visit family? }\end{array}$ & 3 & 2 & I & 0 \\
\hline
\end{tabular}

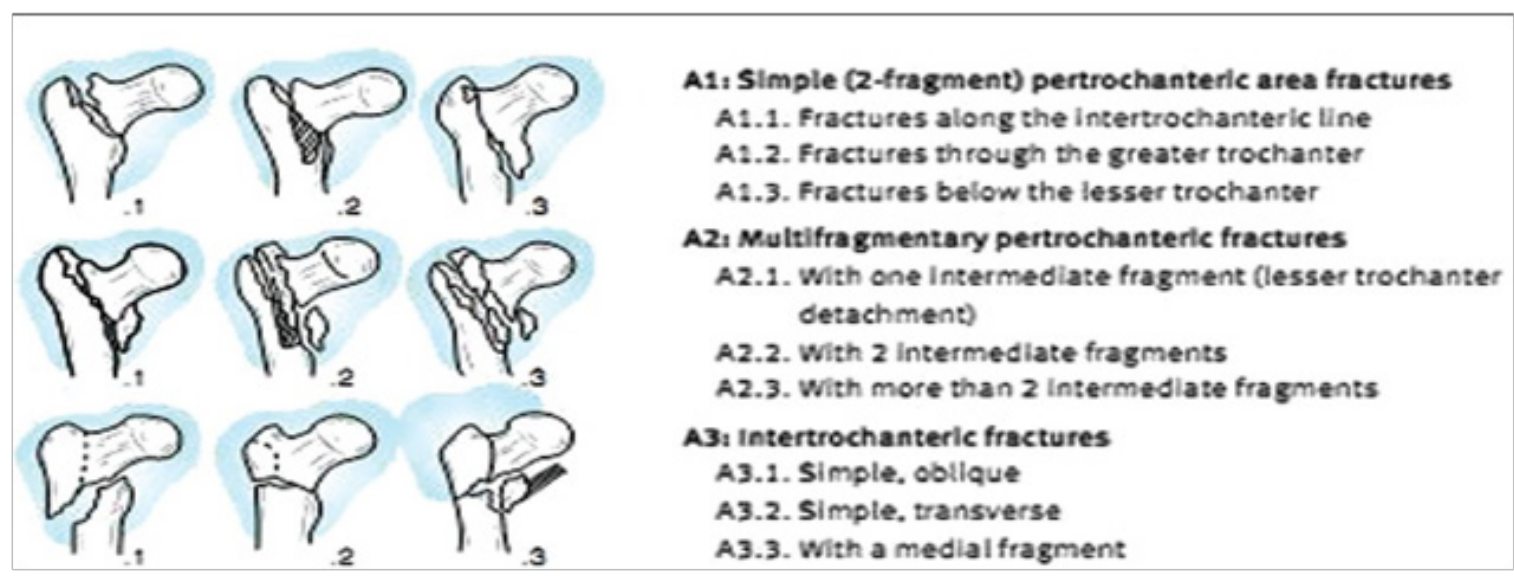

Figure I AO/OTA classification.?

\section{Results}

The mean age of patients was 67 years (between 32-95 years old) with a slight female predominance (sex ratio of 3:2) and an average ASA rating of 2.4 was observed. Preoperative Parker score averaged 6 (ranging from 3 to 9). The right side was the most involved in $70 \%$ of cases, with a predominance of complex and unstable fractures according to AO/OTA classification (83\%) (Table 3). $95 \%$ of injuries were due to standing fall as a result of household accident. The mean time between trauma and surgery was 03 days (12H-6days). The average duration of surgery was 40 minutes (between 20 and $80 \mathrm{~min}$ ) with perioperative blood loss requiring transfusion in $15 \%$ of cases. Early protected ambulation was encouraged on the first postoperative day with partial weight bearing from the second day, and full weight bearing by $3^{\text {rd }}$ postoperative week in $80 \%$ of patients. The average hospital stay was 5 days. Mean bony union time 10 weeks.

Table 3 Fracture pattern and distribution according to AO/OTA classification

\begin{tabular}{lll}
\hline Classification AO & Number of patients & $\%$ \\
\hline Type A I & III & 24 \\
Type A2 & 266 & 59 \\
Type A3 & 73 & 17 \\
\hline
\end{tabular}

Patients were reviewed monthly up to six months and twice a year afterwards. 29(6.4\%) non surgery related (congestive heart disease $\mathrm{n}=15$, acute kidney failure $\mathrm{n}=8$, diabetic ketoacidosis $\mathrm{n}=6$ ) deaths were recorded in the first 6 months whereas 21 patients were lost to follow up. After a mean follow up of 36 months, a total of 400 patients were reviewed with a complete physical and radiological assessment 350 patients $(77 \%)$ achieved union and Parker score averaged 5.5 (ranging from 3 to 8 ).
Patients' folders were reviewed for intraoperative and postoperative complications and how they affected functional outcome. We uncovered 14 intraoperative complications (Figure 2) including 10 failed distal locking: posteriorly placed screws in all cases due to loosening of aiming device yet average parker score was 5 among this group of patients. A single (01) case of cervical guide pin breakage in the femoral head and 3 cases of pelvic penetration of the guide pin led to postoperative peritonitis in one patient and two fatal cases of abdominal hemorrhage that could not be managed intraoperatively.
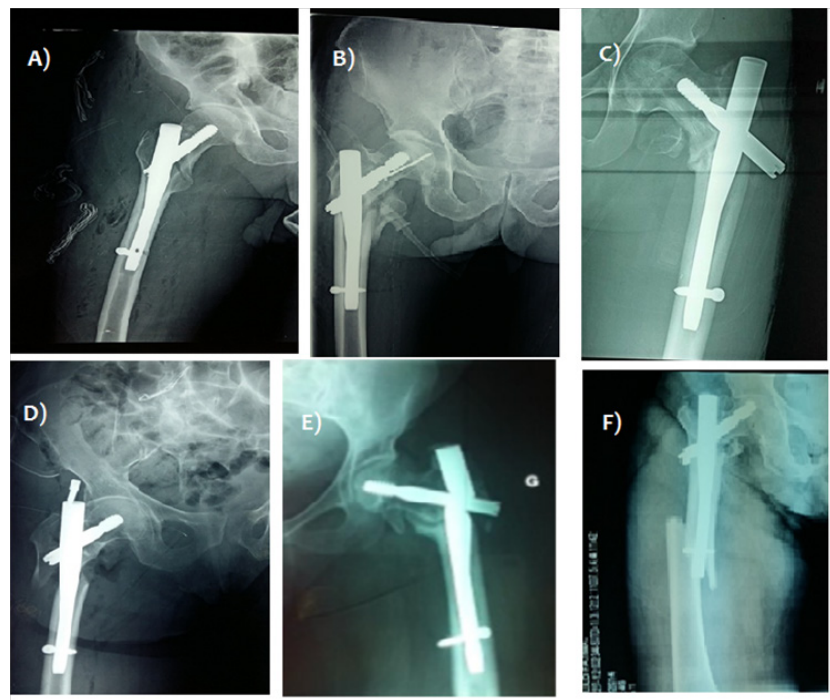

Figure 2 A) Distal locking failure. B) Breakage of the guide pin in the head. C) Displacement of the cervical screw. D) Failure of lag screw blockage. E) Nonunion with gamma implant breakage. F) Proximal diaphyseal femur fracture on one-month postoperative x-ray. 
Postoperative complications were observed in 40 patients $(8.8 \%)$ mainly diaphyseal femoral fractures and cervical screw cut out (Figure 2). 9 cases $(2.2 \%)$ of proximal third diaphyseal fractures occurred between the 1st and 5th postoperative months with fracture line slightly distal to locking screw or tip of nail. All cases underwent nail removal and revision using long gamma nails in 6 cases and a femur nail in 3 cases with favorable outcome (Figure 3 ).
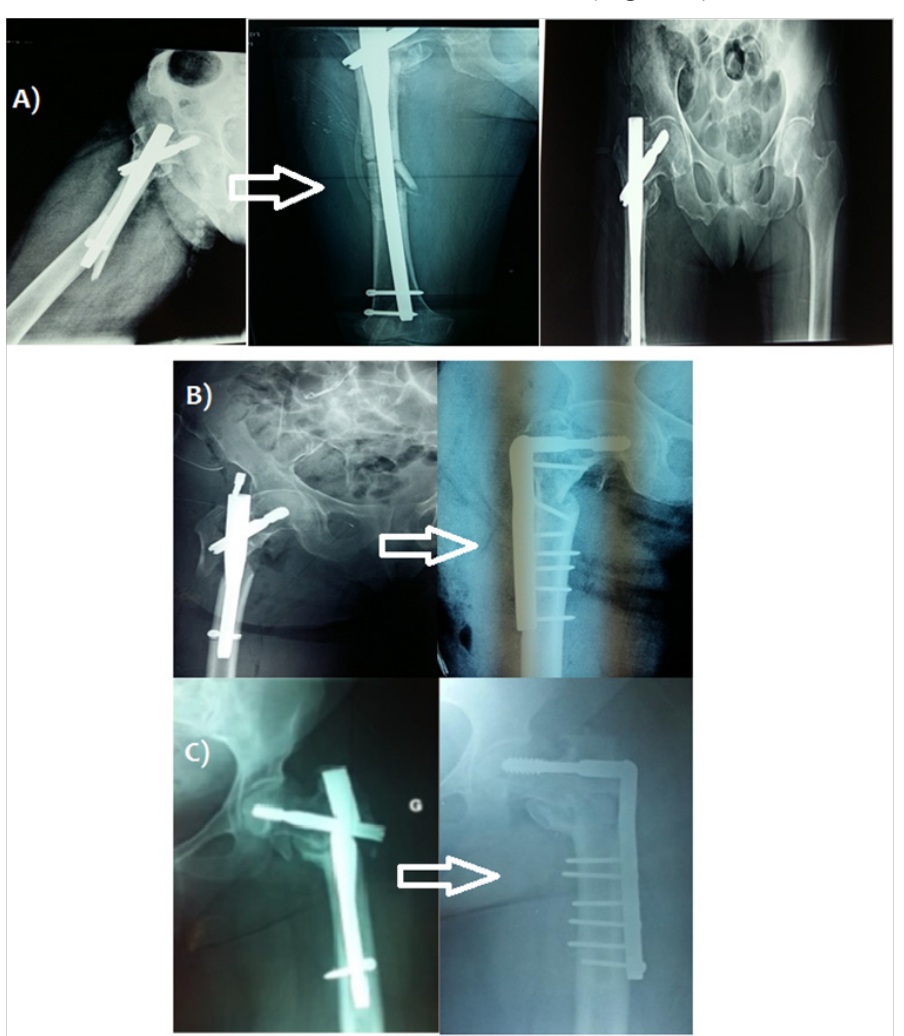

Figure 3 A) Revision surgery using a long gamma nail after diaphyseal femur fracture. B) Revision surgery with a $95^{\circ}$ dynamic condylar screw after gamma nail failure. C) Revision with a $95^{\circ}$ condylar screw after implant breakage complicating a case of non-union.

6 cases $(1.5 \%)$ with cervical screw cut-out were recorded, with immediate postoperative radiography showing bad positioning: cervical screw placement was either too superior or posterior and sometimes even too short. Two cases with acetabular penetration required a total hip arthroplasty, and a single case of revision using a $95^{\circ}$ dynamic condylar plate screw. A case of early secondary displacement of sub trochanteric fracture treated with standard gamma nail underwent revision using a $95^{\circ}$ dynamic condylar with a favorable outcome (Figure 3 ). Two cases $(0.5 \%)$ that failed to unite underwent revision using the conventional $95^{\circ}$ condylar screw plate system. One entailed a sub trochanteric fracture treated with a long gamma nail which required revision surgery after 6 months using a condylar plate screw with iliac crest bone graft. The second case was marked by implant failure and breakage after 5 months requiring revision using conventional dynamic condylar screw system (Figure 3). However, another case of implant breakage with radiological progression of callus was closely monitored and eventually united after 6 months without reoperation (Figure 4).

20 cases of malunion were uncovered notably 8 cases with varus malunion, 6 in valgus and 6 cases with femoral neck shortening.
Nonetheless all cases were well tolerated with little implications on patients' activities of daily living.
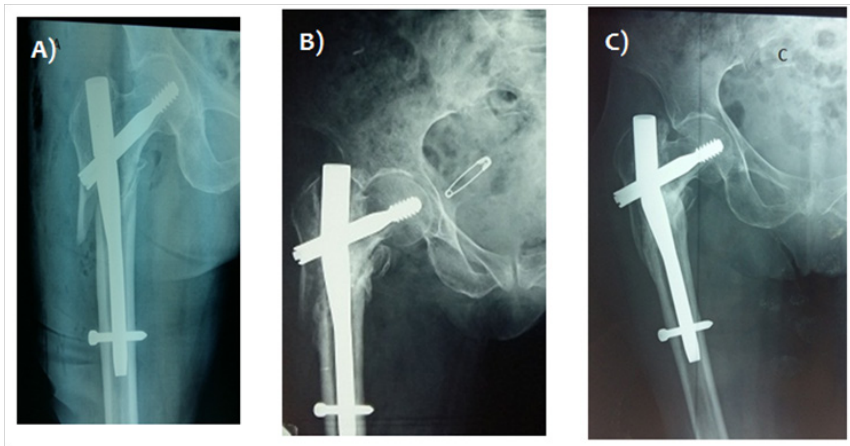

Figure 4 A) Immediate postoperative $x$-ray show AO/OTA 3.I A3 fracture treated with standard gamma nail. B) $\times$ ray image at 4 months postoperative showing nail breakage. C) $x$-ray image at 6 months showing bony union despite implant breakage.

\section{Discussion}

Trochanteric fractures have been treated using a variety of reduction techniques which have developed considerably over the years (10) with a preference for intramedullary implants. From the first osteosynthesis using the Smith-Petersen nail 1930 to the Staca nail plate and Muller's (AO) blade-plate of the 1950's leading to Kuntscher's "Y" nail and Ender's nails as early as 1964. ${ }^{1}$ From 1980 onwards, screw plate systems including the Dynamic Hip Screw ${ }^{\circledR}$ (Synthes) (DHS $\left.{ }^{\circledR}\right)$, were developed, followed by dynamic nail screws such as the Gamma (Stryker $\left.{ }^{\circledR}\right)$ nail from1990 [11]. These newer implants allow for a more stable construct with early weight bearing, ${ }^{12}$ thus consequently reducing morbidity and mortality rates associated with hip fractures in the elderly.

Our mortality rate of $6.4 \%$ at 3 months is similar to those reported in literature, ranging from 7 to $22 \%{ }^{13,14}$ up to $31 \%$ for centenarians. ${ }^{15}$ The advanced age of our population, associated comorbidities and the unstable nature of the fractures in our series may explain this rate. Hommel et al. ${ }^{2}$ identified advanced age, male sex, the presence of associated comorbidities like dementia that could potentially delay primary care as factors that directly influence mortality rate at 12 months after trochanteric fractures.

Overall intraoperative complication rate of $3.1 \%$, and $8.8 \%$ postoperative complication rates were recorded during this period. Intraoperative complications range from $2.2 \%{ }^{16}$ to $10.7 \%,{ }^{17}$ whereas overall postoperative complication are reported to be around $7.2 \%$ and $21 \%^{14,18}$ according to literature. Femoral fracture is one of the most frequent complications with incidence between 2 to $3 \%$ according to some authors. ${ }^{4}$ Rantanen $\mathrm{J}^{19}$ showed that three aspects of gamma implant design: nail curvature, stiffness and diameter were contributory factors. The incidence of femoral fracture on gamma nail insertion has reduced greatly since the advent of $3 \mathrm{rd}$ generation Gamma nails. ${ }^{20}$ Clavert $^{6}$ believes these are likely due technical errors such as:

Untimely distal locking leading to weakening of femoral cortices distal to the nail.

Entry point being too medial or lateral.

Insufficient reaming, less than $2 \mathrm{~mm}>$ nail diameter. 
Inopportune use of hammer for nail advancement.

We reported 9 cases $(2.2 \%)$ of diaphyseal fractures whose lines were located at the distal lock screw or at the end of the nail and are probably due to technical faults. Cervical sliding screw cut-out was the second complication recorded in our series with incidence of $2 \%$. This is defined as a projection of at least $5 \mathrm{~mm}$ of the cervical sliding screw. ${ }^{21}$ It constitutes a multifactorial mechanical failure due to resulting forces applied to the bone, the type of fracture, quality of reduction and implant design. ${ }^{22,23}$ Cases involving cervical screw cut out were attributed to technical error as postoperative X-rays showed inadequate screw positioning either too superior in the AP view, posterior on lateral view or too short in 2 cases. In order to reduce this complication, DOCQUIER ${ }^{5}$ recommends centering the cervical sliding screw in the femoral head on the AP view 5 to $10 \mathrm{~mm}$ from the subchondral bone. Screw placement in the lower half is acceptable in some instances where placement in inferior quadrant is not advisable. On a lateral view, sliding screw should be centered in the femoral head although alternatively, a posterior position is tolerated. Screw cut-out incidence ranges from 0 to $7 \%$ according to literature. ${ }^{24-26}$

Non-union remains a rare complication of trochanteric fractures due to relative good blood supply of the metaphyseal zone. In the event of delayed union, nail dynamization may be a good option. Strict monitoring is required to prevent implant loosening or breakage, which usually occurs at the level of the cervical screw regarded as a zone of weakness. ${ }^{27}$ In our series we observed $02(0.5 \%)$ cases of pseudarthrosis including a case complicated with implant breakage. In recent literature, multicenter studies have reported incidence of Gamma implant failure from $0 \%$ to $0.4 \%{ }^{28-30}$ Average implant breakage time varied between the 6 th and 15 th postoperative month. ${ }^{30}$ The weakest zone of the Gamma nail remains the point of the cephalic sliding screw. This critical zone is where the vast forces from the femoral neck are transmitted to the diaphyseal region. ${ }^{29,31}$ Thus, recurrent pain the around the screw location on the operated hip must be considered as clinical signs of implant failure or possible breakage. The authors recommend hip x-rays in at least two views as part of routine follow-up in the event of dynamisation for delayed union on gamma nail. Overall, our long medium term outcomes are similar to those reported in literature, with overall revision rate of $4.2 \%$ is comparable to revision rates from $1.4 \%{ }^{32}$ to $8 \%{ }^{25}$ according to recent literature.

\section{Conclusion}

Operative treatment of extracapsular hip fractures using the Gamma nail represents a valid technique, albeit with its peculiar operative technique yet remains highly applicable even in unstable fractures with less morbidity through closed reduction and miniinvasive approach. Its mechanical advantage allows early weight bearing in most cases. Malunion still pose a considerable setback as far as radiographic outcomes are concerned with little to no functional implications on long term outcomes. All types of trochanteric fractures are thus amenable to fixation using the gamma nail. Careful scrutiny of pre-operative x-rays, anatomical reduction and rigorous technique would go a long way to reduce per and postoperative complications.

\section{Declarations}

Ethics approval and consent to participate

The Hassan II Teaching Hospital's review board approved the publication of the study

\section{Consent to publish}

Written informed consent was obtained from the patients involved in this case series for publication of the research and its associated images

Availability of data and materials: Not applicable

\section{Conflicts of interests}

The authors declare no potential conflict of interest in relation to the authorship and publication of this article.

\section{Funding}

Not applicable.

\section{Contribution of authors}

All authors contributed to the writing of the manuscript. All authors read and approved the final version of the manuscript.

\section{References}

1. Isida R, Bariatinsky V, Kern G, et al. Prospective study of the reproducibility of $\mathrm{X}$-rays and $\mathrm{CT}$ scans for assessing trochanteric fracture comminution in the elderly: a series of 110 cases. Eur J Orthop Surg Traumatol. 2015;25(7):1165-1170.

2. Hommel A, Ulander $\mathrm{K}$, Bjorkelund $\mathrm{KB}$, et al. Influence of optimised treatment of people with hip fracture on time to operation, length of hospital stay, reoperations and mortality within 1 year. Injury. 2008;39(10):1164-1174.

3. Haleem S, Lutchman L, Mayahi R, et al. Mortality following hip fracture: trends and geographical variations over the last 40 years. Injury. 2008;39(10):1157-1163

4. Soucanye de Landevoisin E, Bertani A, Candoni P, et al. Proximal femoral nail antirotation (PFN-ATM) fixation of extra-capsular proximal femoral fractures in the elderly: retrospective study in 102 patients. Orthop Traumatol Surg Res. 2012;98(3):288-295.

5. Docquier PL, Manche E, Autrique JC, et al. Complications associated with gamma nailing. A review of 439 cases. Acta Orthop Belg. 2002;68(3):251-257.

6. Forthomme JP, Costenoble V, Soete P, et al. Treatment of trochanteric fractures of the femur using the gamma nail (apropos of a series of 92 cases. Acta Orthop Belg. 1993;59(1):22-29.

7. Sidi A, Lobato EB, Cohen JA. The American Society of Anesthesiologists' Physical Status: category V revisited. J Clin Anesth. 2000;12(4):328334.

8. Parker MJ, Pryor GA, Anand JK, et al. A comparison of presenting characteristics of patients with intracapsular and extracapsular proximalfemoral fractures. J R Soc Med. 1992;85(3):152-155.

9. Müller ME. Classification and international AO-documentation of femur fractures. Unfallheilkunde. 1980;83(5):251-259.

10. Waast D, Touraine D, Wessely L, et al. Pertrochanteric fractures in elderly subjects aged over 75. Rev Chir Orthop Reparatrice Appar Mot. 2007;93(4 Suppl):2S33-46.

11. Kempf I, Grosse A, Taglang G, et al. Gamma nail in the treatment of closed trochanteric fractures. Results and indications apropos of 121 cases. Rev Chir Orthop Reparatrice Appar Mot. 1993;79(1):29-40.

12. Saarenpää I, Heikkinen T, Jalovaara P. Treatment of subtrochanteric fractures. A comparison of the Gamma nail and the dynamic hip screw: short-term outcome in 58 patients. Int Orthop. 2007;31(1):65-70. 
13. Parker MJ, Pryor GA, Myles J. 11-year results in 2,846 patients of the Peterborough Hip Fracture Project: reduced morbidity, mortality and hospital stay. Acta Orthop Scand. 2000;71(1):34-38.

14. Mnif H, Koubaa M, Zrig M, et al. Elderly patient's mortality and morbidity following trochanteric fracture. A prospective study of 100 cases. Orthop Traumatol Surg Res. 2009;95(7):505-510.

15. Forster MC, Calthorpe D. Mortality following surgery for proximal femoral fractures in centenarians. Injury. 2000;31(7):537-539.

16. Bellabarba C, Herscovici D Jr, Ricci WM. Percutaneous treatment of peritrochanteric fractures using the Gamma nail. Clin Orthop Relat Res. 2000;(375):30-42.

17. Habernek H, Wallner T, Aschauer E, et al. Comparison of Ender nails, dynamic hip screws, and gamma nails in the treatment of peritrochanteric femoral fractures. Orthopedics. 2000;23:121-127.

18. Leung KS, Chen CM, So WS, et al. Multicenter trial of modified Gamma nail in East Asia. Clin Orthop Relat Res. 1996;(323):146-154.

19. Rantanen J, Aro HT. Intramedullary fixation of high subtrochanteric femoral fractures: a study comparing two implantdesigns, the Gamma nail and the intramedullary hip screw. J Orthop Trauma. 1998;12(4):249252 .

20. Bhandari M, Schemitsch E, Jönsson A, et al. Gamma nails revisited: gamma nails versus compression hip screws in the management of intertrochanteric fractures of the hip: a meta-analysis. J Orthop Trauma. 2009;23(6):460-464.

21. Waast D, Touraine D, Wessely L, Ropars M, Coipeau P, Perrier C, Guillot P. Pertrochanteric fractures in elderly subjects aged over 75. Rev Chir Orthop Reparatrice Appar Mot. 2007;93(4 Suppl):2S33-46.

22. Sommers MB, Roth $\mathrm{C}$, Hall $\mathrm{H}$, et al. A laboratory model to evaluate cutout resistance of implants for pertrochanteric fracture fixation. $J$ Orthop Trauma. 2004;18(6):361-368.

23. Gadegone WM, Salphale YS. Proximal femoral nail - an analysis of 100 cases of proximal femoral fractures with an average follow up of 1 year. Int Orthop. 2007;31(3):403-408
24. Lahoud JC, Asselineau A, Salengro S, et al. Sub-trochanteric fractures. A comparative study between gamma nail and angular osteosynthesis with lateral cortical support. Rev Chir Orthop Reparatrice Appar Mot. 1997;83(4):335-342.

25. Madsen JE, Naess L, Aune AK, et al. Dynamic hip screw with trochanteric stabilizing plate in the treatment of unstable proximal femoralfractures: a comparative study with the Gamma nail and compression hip screw. $J$ Orthop Trauma. 1998;12(4):241-248.

26. Baumgaertner MR, Curtin SL, Lindskog DM, et al. The value of the tipapex distance in predicting failure of fixation of peritrochanteric fractures of the hip. J Bone Joint Surg Am. 1995;77(7):1058-1064.

27. Sbiyaa M, El Alaoui A, Admi M, et al. Intertrochanteric fracture non-unions with implant failure of the gamma nail. Pan Afr Med J. 2016;23:57.

28. Boriani S, De Iure F, Bettelli G, et al. The results of a multicenter Italian study on the use of the Gamma nail for the treatment of pertrochanteric and subtrochanteric fractures: a review of 1181 cases. Chir Organi Mov. 1994;79(2):193-203.

29. Gaebler C, Stanzl-Tschegg S, Tschegg EK, et al. Implant failure of the gamma nail. Injury. 1999;30(2):91-99.

30. van den Brink WA, Janssen IM. Failure of the gamma nail in a highly unstable proximal femur fracture: report of four cases encountered in The Netherlands. J Orthop Trauma. 1995;9(1):53-56.

31. Seral B, García JM, Cegoñino J, et al. Finite element study of intramedullary osteosynthesis in the treatment of trochanteric fractures of the hip: Gamma and PFN. Injury. 2004;35(2):130-135.

32. Andress HJ, Forkel H, Grubwinkler M, et al. Treatment of per- and subtrochanteric femoral fractures by gamma nails and modular hip prostheses. Differential indications and results. Unfallchirurg. 2000;103(6):444-451. 